\title{
ROLE OF DIAGNOSTIC HYSTEROSCOPY IN INFERTILE WOMEN WITH NORMAL HYSTEROSALPINGOGRAM
}

\author{
By \\ Amr M. Sleem, EL-Sayed M. Taha and Ahmed S. Mohamed \\ Department of Obstetrics and Gynecology, Faculty of Medicine, Al-Azhar University \\ Corresponding author: Amr M. Sleem; \\ Mobile: 01097458366, E-mail: dramrmansour28@yahoo.com
}

\begin{abstract}
Background: The indication for routine hysteroscopy (HSC) in patients undergoing diagnostic hysteroscopy as part of an infertility work up is still a matter of controversy. Although most clinics continue to use hysterosalpingography (HSG) as their routine test to assess the uterine cavity, there is a growing body of literature dealing with the use of HSC as an important instrument to use in the evaluation and treatment of infertile couples.
\end{abstract}

Objective: To evaluate the role of the diagnostic hysteroscopy in infertile women with normal HSG.

Patients and Methods: This cohort observational study was carried out at Ahmed Maher Teaching Hospital, Egypt, from November 2019 till May 2020, on one hundred women Patients having primary infertility.

Results: The mean age of the studied cases was $29.58 \pm 6.75$ with range (20-40). The mean period of infertility was $4.89 \pm 1.07$ with range (3-7), the mean BMI was $28.27 \pm 2.13$ with range (25-32). There were $10 \%$ illiterate, $45 \%$ with moderate education and $45 \%$ with high education, there were $92 \%$ Primigravida and $8 \%$ multigravida, and there were $92 \%$ with primary type of infertility, and $8 \%$ with secondary type of infertility. There were $17 \%$ with diabetes, $28 \%$ with hypertension and $13 \%$ with previous pelvic surgery. Among the studied cases, there were 38 with detected abnormality, i.e. (5\%) endometrial polyp, (2\%) Cervical Polyp, (6\%) cervical stenosis, (3\%) chronic endometritis, (3\%) hypertrophic endometrium, (2\%) atrophic endometrium, (5\%) Intrauterine adhesions, (4\%) Cornual fibrosis, (2\%) cornual inflammation, (4\%) Sub mucous myoma and $(2 \%)$ septum. There was no significant difference between the cases who detected abnormality and who didn't as regard age, period of infertility, BMI, education, parity and type of infertility. There was no significant difference between the cases who detected abnormality and who didn't as regard menstrual history. There was no significant difference between the cases who detected abnormality and who didn't as regard diabetes, hypertension and previous pelvic surgery.

Conclusion: The incidence of uterine pathologies (congenital and acquired) in women with primary or secondary infertility approximated $30 \%$, thus, justifying, the use of diagnostic hysteroscopy in the primary routine investigation of infertile women.

Key words: Diagnostic hysteroscopy, infertility, normal hysterosalpingogram.

\section{INTRODUCTION}

Infertility means the inability to conceive following 1 year of unprotectedintercourse in cases where the female is $>35$ years of age or following 6 months of unprotected intercourse for women $<35$ years of age (Anwar and Anwar, 2016).

Hysteroscopy is considered the gold standard for evaluating the uterine cavity, and due to improved endoscopic developments. It can be performed 
reliably and safely as an office procedure (Pundir and El Toukhy, 2010).

The presence of uterine pathology may negatively affect the chance of implantation. The prevalence of unsuspected uterine pathology in asymptomatic women with implantation failure has been reported to be as high as $50 \%$. Therefore, one of the common investigations proposed for women undergoing IVF treatment is to evaluate the uterine cavity via hysteroscopy (Cenksoy et al., 2013).

The role of congenital uterine anomalies in infertility remains unclear. However, it has been suggested that uterine anomalies may contribute to infertility, possibly by interfering with normal implantation and placentation ( $E l$ Mazny et al., 2011).

HSG is a contrast study of the uterine cavity and fallopian tubes. It is a simple, inexpensive, safe, and rapid diagnostic procedure that, when performed properly, provides valuable information about the uterine cavity and tubal architecture (Gajbhiye and Gajbhiye, 2017).

Hysterography is used predominantly in the evaluation of infertility and recurrent abortion. Also, this procedure can be used in other cases, such as; Chronic pelvic pain, congenital or anatomical uterine abnormalities and abnormal uterine bleeding (AUB) (Johnstone and Olpin, 2018).

HSG must be timed to be done between complete cessation of menstruation and ovulation. This will avoid the risk of disturbing a luteal phase pregnancy. Such timing also avoids radiation exposure to the oocyte that will resume meiosis after the luteinizing hormone surge. Therefore, HSG ideally should be scheduled between day 4 and 7 of the menstrual cycle. This allows time for any residual blood from the menses to clear yet is early enough so that the endometrium has not grown significantly (Park and Isaacson, 2017).

The aim of this study was to evaluate the role of the diagnostic hysteroscopy in infertile women with normal HSG.

\section{PATIENTS AND METHODS}

This cohort observational study was carried out on one hundred women having infertility at Ahmed Maher Teaching Hospital, Egypt. Cases were recruited from the outpatient Infertility clinic from December 2019 till May 2020.

\section{Inclusion Criteria:}

Patients aged 20-35years, having primary or secondary infertility, women with infertility for more than 1 year, normal hystrosalpingiogram, regular cycle and no male factor.

\section{Exclusion Criteria:}

Patient with ages less than 20 years or more than 40 years, contraindications of hysteroscopy like bleeding, suspected or confirmed pregnancy and history suggestive of active infection like history of cervical or vaginal discharge, patients with abnormal HSG and couples with male factor infertility (abnormal semen parameters and/or sexual dysfunctions).

All study patients were subjected to: Full history taking, clinical examination, and blood analysis for a base line hormonal profile- day 2 serum FSH, LH, and prolactin, ultrasonographic examination and hysteroscopic 
examination. Rrigid continuous flow diagnostic hysteroscopy was done (Tuttligen, Karl Storz, Germany). It has a 30o panoramic optic which was $4 \mathrm{~mm}$ in diameter and the diagnostic continuous flow outer sheath was $6.5 \mathrm{~mm}$ in diameter. The patient was placed in lithotomy position with the buttocks projecting slightly beyond the table edge.

Statistical analysis was done using Statistical Package for the Social Sciences version 20 (SPSSInc., Chicago, IL, USA). Quantitative variables were described in the form of mean and standard deviation, median and interquartile range (IQR). Qualitative variables were described as number and percent. In order to compare parametric quantitative variables between two groups, Student t test was performed. Qualitative variables were compared using chi-square (X2) test or Fisher's exact test when frequencies were below five. $\mathrm{P}$ value $<0.05$ was considered significant.

An informed verbal consent from all participants was taken and confidentiality of information was assured.

Permission from the Faculty of Medicine ethical committee was obtained and approval from institutional review board was taken. 


\section{RESULTS}

The mean age of the studied cases was $29.58 \pm 6.75$ with range (20-40). The mean period of infertility was $4.89 \pm 1.07$ with range (3-7). The mean BMI was $28.27 \pm 2.13$ with range (25-32). There 10 $(10 \%)$ were illiterate, $45(45 \%)$ with moderate education, and $45(45 \%)$ with high education. There were 92 (92\%) primigravida and $8(8 \%)$ multigravida, there were $92(92 \%)$ with primary type of infertility, and $8(8 \%)$ with secondary type of infertility. There were $7(7 \%)$ with diabetes, $8(8 \%)$ with hypertension and 3 (3\%) with previous pelvic surgery (Table 1).

Table (1): Distribution of the studied cases according to personal and past history $(n=100)$

\begin{tabular}{|c|c|c|c|c|}
\hline $\begin{array}{ll}\text { Parameters } & \text { Distribution } \\
\end{array}$ & \multicolumn{2}{|c|}{ No. } & \multicolumn{2}{|c|}{$\%$} \\
\hline \multicolumn{5}{|l|}{ Age (years) } \\
\hline Min. - Max. & \multicolumn{4}{|c|}{$20.0-40.0$} \\
\hline Mean \pm SD. & \multicolumn{4}{|c|}{$29.58 \pm 6.75$} \\
\hline Median (IQR) & \multicolumn{4}{|c|}{$30.0(23.0-35.50)$} \\
\hline \multicolumn{5}{|l|}{ Period of infertility } \\
\hline Min. - Max. & \multicolumn{4}{|c|}{$3.0-7.0$} \\
\hline Mean \pm SD. & \multicolumn{4}{|c|}{$4.89 \pm 1.07$} \\
\hline Median (IQR) & \multicolumn{4}{|c|}{$5.0(4.0-6.0)$} \\
\hline \multicolumn{5}{|l|}{ BMI $\left(\mathrm{kg} / \mathrm{m}^{2}\right)$} \\
\hline Min. - Max. & \multicolumn{4}{|c|}{$25.0-32.0$} \\
\hline Mean \pm SD. & \multicolumn{4}{|c|}{$28.27 \pm 2.13$} \\
\hline Median (IQR) & \multicolumn{4}{|c|}{$28.05(26.25-29.90)$} \\
\hline \multicolumn{5}{|l|}{ Education } \\
\hline None & \multicolumn{2}{|c|}{10} & \multicolumn{2}{|c|}{10.0} \\
\hline Moderate & \multicolumn{2}{|c|}{45} & \multicolumn{2}{|c|}{45.0} \\
\hline High level & \multicolumn{2}{|c|}{45} & \multicolumn{2}{|c|}{45.0} \\
\hline \multicolumn{5}{|l|}{ Parity } \\
\hline $\mathbf{0}$ & \multicolumn{2}{|c|}{92} & \multicolumn{2}{|c|}{92.0} \\
\hline 1 & \multicolumn{2}{|c|}{8} & \multicolumn{2}{|c|}{8.0} \\
\hline \multicolumn{5}{|l|}{ Type of infertility } \\
\hline Primary & \multicolumn{2}{|c|}{92} & \multicolumn{2}{|c|}{92.0} \\
\hline \multirow[t]{3}{*}{ Secondary } & \multicolumn{2}{|c|}{8} & \multicolumn{2}{|c|}{8.0} \\
\hline & \multicolumn{2}{|c|}{ No } & & \\
\hline & No. & $\%$ & No. & $\%$ \\
\hline Diabetes & 93 & 93.0 & 7 & 7 \\
\hline Hypertension & 92 & 92.0 & 8 & 8.0 \\
\hline Previous pelvic surgery & 97 & 97.0 & 3 & 3.0 \\
\hline
\end{tabular}

Among the studied cases, there were 38 (38) with detected abnormality $\{(5 \%)$ endometrial polyp, (5\%) cervical Polyp, (3\%) cervical stenosis, (5\%) chronic endometritis, (3\%) hypertrophic endometrium, endometrium, $(5 \%)$ atrophic intrauterine adhesions, (2\%) cornual fibrosis, (2\%) cornual inflammation, (4\%) sub mucous myoma and (2\%) septum\} (Table 2). 
Table (2): Distribution of the studied cases according to detected abnormality and hysteroscopic findings $(n=100)$

\begin{tabular}{|l|c|c|}
\hline Detected abnormality Distribution & No. & $\%$ \\
\hline No & 62 & 62.0 \\
\hline Yes & 38 & 38.0 \\
\hline Abnormal hysteroscopic findings & & \\
\hline None & 62 & 62.0 \\
\hline Endometrial Polyp & 5 & 5.0 \\
\hline Cervical Polyp & 5 & 5.0 \\
\hline Cervical stenosis & 3 & 3.0 \\
\hline Chronic endometritis & 6 & 6.0 \\
\hline Hypertrophic endometrium & 3 & 3.0 \\
\hline Atrophic endometrium & 4 & 4.0 \\
\hline Intrauterine adhesions & 2 & 2.0 \\
\hline Cornual fibrosis & 2 & 2.0 \\
\hline Cornual inflammation & 2 & 2.0 \\
\hline Sub mucous myoma & 4 & 4.0 \\
\hline Septum & 2 & 2.0 \\
\hline
\end{tabular}

There was no significant difference between the cases who detected period of infertility, BMI, education, parity and type of infertility (Table 3). abnormality and who didn't as regard age,

Table (3): Relation between detected abnormality and personal history $(n=100)$

\begin{tabular}{|c|c|c|c|c|c|}
\hline \multirow{3}{*}{$\begin{array}{l}\text { Detected abnormality } \\
\text { Parameters }\end{array}$} & \multirow{2}{*}{\multicolumn{2}{|c|}{ No $(n=62)$}} & \multirow{2}{*}{\multicolumn{2}{|c|}{ Yes $(n=38)$}} & \multirow{3}{*}{$\mathrm{P}$} \\
\hline & & & & & \\
\hline & No. & $\%$ & No. & $\%$ & \\
\hline \multicolumn{6}{|l|}{ Age (years) } \\
\hline Min. - Max. & \multicolumn{2}{|c|}{$20.0-40.0$} & \multicolumn{2}{|c|}{$20.0-40.0$} & \multirow{3}{*}{0.648} \\
\hline Mean \pm SD. & \multicolumn{2}{|c|}{$29.82 \pm 6.60$} & \multicolumn{2}{|c|}{$29.18 \pm 7.04$} & \\
\hline Median (IQR) & \multicolumn{2}{|c|}{$30.0(24.0-35.0)$} & \multicolumn{2}{|c|}{$29.0(23.0-36.0)$} & \\
\hline \multicolumn{6}{|l|}{ Period of infertility } \\
\hline Min. - Max. & \multicolumn{2}{|c|}{$3.0-7.0$} & \multicolumn{2}{|c|}{$3.0-6.0$} & \multirow{3}{*}{0.466} \\
\hline Mean \pm SD. & \multicolumn{2}{|c|}{$4.95 \pm 1.11$} & \multicolumn{2}{|c|}{$4.79 \pm 1.02$} & \\
\hline Median (IQR) & \multicolumn{2}{|c|}{$5.0(4.0-6.0)$} & \multicolumn{2}{|c|}{$5.0(4.0-6.0)$} & \\
\hline \multicolumn{6}{|l|}{ BMI $\left(\mathrm{kg} / \mathrm{m}^{2}\right)$} \\
\hline Min. - Max. & \multicolumn{2}{|c|}{$25.0-31.80$} & \multicolumn{2}{|c|}{$25.30-32.0$} & \multirow{3}{*}{0.840} \\
\hline Mean \pm SD. & \multirow{2}{*}{\multicolumn{2}{|c|}{$\begin{array}{c}28.24 \pm 2.09 \\
28.05(26.20-29.70)\end{array}$}} & \multicolumn{2}{|c|}{$28.33 \pm 2.23$} & \\
\hline Median (IQR) & & & 28.15 & $-30.40)$ & \\
\hline \multicolumn{6}{|l|}{ Education } \\
\hline None & 6 & 9.7 & 4 & 10.5 & \multirow{3}{*}{0.679} \\
\hline Middle & 30 & 48.4 & 15 & 39.5 & \\
\hline High level & 26 & 41.9 & 19 & 50.0 & \\
\hline \multicolumn{6}{|l|}{ Parity } \\
\hline 0 & 57 & 91.9 & 35 & 92.1 & $\mathrm{FE}_{\mathrm{p}}=$ \\
\hline 1 & 5 & 8.1 & 3 & 7.9 & 0.976 \\
\hline \multicolumn{6}{|l|}{ Type of infertility } \\
\hline Primary & 57 & 91.9 & 35 & 92.1 & $\mathrm{FE}_{\mathrm{p}}=$ \\
\hline Secondary & 5 & 8.1 & 3 & 7.9 & 0.976 \\
\hline
\end{tabular}


There was no significant difference between the cases who detected abnormality as regard diabetes, hypertension and previous pelvic surgery (Table 4).

Table (4): Relation between detected abnormality and past history $(n=100)$

\begin{tabular}{|c|c|c|c|c|c|c|}
\hline \multirow{2}{*}{$\begin{array}{l}\text { Detected abnormality } \\
\text { Parameters }\end{array}$} & \multicolumn{2}{|c|}{ No $(n=62)$} & \multicolumn{2}{|c|}{ Yes $(\mathbf{n}=38)$} & \multirow{2}{*}{$\chi^{2}$} & \multirow{2}{*}{$\mathrm{P}$} \\
\hline & No. & $\%$ & No. & $\%$ & & \\
\hline \multicolumn{7}{|l|}{ Diabetes } \\
\hline No & 52 & 83.9 & 31 & 81.6 & \multirow{2}{*}{0.088} & \multirow{2}{*}{0.767} \\
\hline Yes & 10 & 16.1 & 7 & 18.4 & & \\
\hline \multicolumn{7}{|l|}{ Hypertension } \\
\hline No & 45 & 72.6 & 27 & 71.1 & \multirow{2}{*}{0.027} & \multirow{2}{*}{0.869} \\
\hline Yes & 17 & 27.4 & 11 & 28.9 & & \\
\hline \multicolumn{7}{|l|}{ Previous pelvic surgery } \\
\hline No & 55 & 88.7 & 32 & 84.2 & \multirow{2}{*}{0.422} & ${ }^{\mathrm{FE}} \mathrm{p}=$ \\
\hline Yes & 7 & 11.3 & 6 & 15.8 & & 0.516 \\
\hline
\end{tabular}

\section{DISCUSSION}

The role of hysteroscopy in infertility investigation is to detect possible intrauterine changes that could interfere with implantation or growth or both, of the conceptus (Cenksoy et al., 2013). So, this study was selected to be conducted to evaluate the role of the diagnostic hysteroscopy in infertile women with normal HSG.

The mean age of the studied cases was $29.58 \pm 6.75$ with range (20-40), the mean period of infertility was $4.89 \pm 1.07$ with range (3-7), the mean BMI was $28.27 \pm$ 2.13 with range (25-32), there were 10 $(10 \%)$ was illiterate, $45(45 \%)$ with moderate education and $45(45 \%)$ with high education, there were $92(92 \%)$ Primigravida and $8(8 \%)$ multigravida and there were $92(92 \%)$ with Primary type of infertility and $8(8 \%)$ with Secondary type of infertility.

Our results were supported by study of Amirian et al. (2019) as they reported that the mean age of the attending patients and their duration of infertility were $30.9 \pm 5.4$ and $4.1 \pm 5.2$ years, respectively. There were $71.8 \%$ of them with primary type of infertility. Furthermore, Wadhwa et al. (2017) revealed that a majority of $73.14 \%$ had primary infertility and $26.85 \%$ had secondary infertility.

The current study showed that among the studied cases, there were $5 \%$ detected endometrial polyp, (2\%) cervical polyp, $(6 \%)$ cervical stenosis, (3\%) chronic endometritis, (3\%) hypertrophic endometrium, (2\%) atrophic endometrium, (5\%) intrauterine adhesions, (4\%) cornual fibrosis, (2\%) cornual inflammation, (4\%) sub mucous myoma and (2\%) septum.

Our results were supported by study of Muhammad et al. (2016) as they reported that during hysteroscopic examination, abnormalities were detected in the cervix and uterus in 48 patients $(34.3 \%)$. More than one abnormality was seen in 8 patients, i.e. 56 abnormalities were recorded, Cervical abnormalities $(\mathrm{n}=12)$ represented $21.4 \%$ of all abnormalities, while uterine abnormalities were 44 , 
representing $78.6 \%$ all abnormalities. Cervical stenosis was the most frequent hysteroscopic findings, 9 cases was detected. Cervical stenosis and cervical polyp were seen in $21.3 \%$ of cases. The 2 cases with uterine septa had small septum. Intrauterine adhesions were found in 8 patients; 6 with mild adhesions and 2 with moderate adhesions. Cervical stenosis did not hinder passage of the hysteroscope to inspect the uterine cavity in the 9 cases.

Further, Godinjak and Idrizbegovic (2018) examined infertile patients using hormonal tests, cervical smear, sonography, Chlamydia antibody, and normal semen analysis. Laparoscopy and hysteroscopy were performed in the follicular phase for all the patients within the age range of 23-42 years whose means of age and infertility duration was 31 and 6.3 years, respectively. Based on the results, hysteroscopy was normal in $75.11 \%$, while it was found abnormal in the remaining $24.89 \%$. Uterine pathologies involved submucosal myomas $11.6 \%$, endometrial polyp cases $7.22 \%$. Asherman syndrome cases in $0.8 \%$, and uterine anomaly cases in $5.27 \% .20 \%$ of uterine pathologies with short time and low complication (less than $0.01 \%$ ) were diagnosed simultaneously performing hysteroscopy and laparoscopy.

In the study of El Huseiny and Soliman (2013), normal hysteroscopic findings were reported in $79.63 \%$. The other $20.37 \%$ were with abnormal hysteroscopy. The most common reported hysteroscopic abnormality was intrauterine adhesions (IUA) in $31.81 \%$ followed by endometrial polyp $26.13 \%$. Pre-hysteroscopic uterine investigations (ultrasound or hysterography) were available. Office hysteroscopy revealed uterine cavity abnormalities in $14.68 \%$. Of those with abnormal pre-hysteroscopic findings, hysteroscopy examinations were normal in $25 \%$ of patients.

In another study by Nigam et al. (2015), infertile women with primary infertility received $\mathrm{HSG}$ which was found to be abnormal in $78.1 \%$ while being normal in $21.9 \%$. Then, laparoscopy and hysteroscopy were conducted in patients with normal HSG. The diagnosed pathologies contained uterine adhesions in $90 \%$ and an endometrial polyp in $10 \%$. The false negative percentage was reported $12.69 \%$ for the HSG.

In the same vein, Chauhan et al. (2013) found that the mean age and duration of infertility of the patients were $30 \pm 4$ and $4.1 \pm 2$ years, respectively. The sensitivity, specificity, PPV, and NPV of the hysteroscopy were $50 \%, 98 \%, 76.9 \%$, and $88.5 \%$, respectively.

In the study in our hands, there was no significant difference between the cases who detected abnormality and who didn't as regard age, period of infertility, BMI, education, Parity and Type of infertility. There was no significant difference between the cases who detected abnormality and who didn't as regard menstrual history. There was no significant difference between the cases who detected abnormality and who didn't as regard diabetes, hypertension and previous pelvic surgery.

There was no significant difference between the cases who detected abnormality and who didn't as regard pulse, temp, systolic and diastolic BP. 
Our results were supported by study of Pansky et al. (2016) as they reported that endometrial polyps were diagnosed in both primary and secondary infertility groups with no statistically significant difference. The true incidence of endometrial polyps in the general population is difficult to determine, because many of them are clinically asymptomatic. No significant difference was found in the rate of intrauterine adhesions comparing the patients with primary versus secondary infertility, in spite of the known relationship between secondary infertility and the existence of adhesions, being mostly the result of uterine curettage for postpartum or post abortion residua.

Furthermore, Wadhwa et al. (2017) found that abnormal hysteroscopic findings were detected in $35.44 \%$ of women with primary infertility and in $35.71 \%$ women with secondary infertility. The difference between two groups was not statistically significant.

In the study of Amirian et al. (2019), the type of infertility made no significant difference in diagnosing uterine pathology in the hysteroscopy.

Hysteroscopy, with the development and miniaturization of equipment, is currently simple, outpatient cost-effective exploration and it is considered the gold standard for diagnosis of intrauterine lesions. However, the benefit of the systematic use of hysteroscopy in the initial assessment of infertility remains unclear and the exploration of the uterine cavity in the initial assessment of infertility should be based on hysterosalpingography or Hyster sonography. Systematic hysteroscopy before IVF is widely accepted practice that is supposed to improve pregnancy rates but still lacks scientific evidence. After repeated implantation failure in IVF cycles, uterine cavity should be reevaluated by hysteroscopy and this practice has been demonstrated to improve pregnancy rates (Ait et al., 2010).

\section{CONCLUSION}

Diagnostic hysteroscopy has a similar importance in the evaluation of patients with both primary and secondary infertility.

\section{REFERENCES}

1. Ait YB, Gervaise $A$ and Fernandez $H$. (2010): Which is the method of choice for evaluating uterine cavity in infertility workup?. Journal de gynecologie, obstetrique et biologie de la reproduction, 39(8): 606-613.

2. Amirian M, Mohammadabad AD, Morovatdar N and Hafizi L. (2019): Investigating Hysteroscopy Implementation in Infertile Women Candidate With a Normal Uterine Cavity for Laparoscopy in Hysterosalpingography. International Journal of Women Health and Reproduction Sciences, 7(1), 79-84.

3. Anwar S and Anwar A. (2016): Infertility: a review on causes, treatment and management. Women's Health Gynecol, 5, 2-11.

4. Cenksoy P, Ficicioglu C, Yıldırım G and Yesiladali M. (2013): Hysteroscopic findings in women with recurrent IVF failures and the effect of correction of hysteroscopic findings on subsequent pregnancy rates. Archives of gynecology and obstetrics, 287(2): 357-360.

5. Chauhan MB, Lakra $P$, Nanda $S$, Malik $R$, and Malhotra V. (2013): Hysterosalpingography vs hysteroscopy: role in assessment of uterine factor during infertility workup. J SAFOG, 5(3):116-9.

6. El Huseiny AM and Soliman BS. (2013): Hysteroscopic findings in infertile women: a retrospective study. Middle East Fertility Society Journal, 18(3), 154-158. 
7. El-Mazny A, Abou-Salem N, El-Sherbiny W and Saber W. (2011): Outpatient hysteroscopy: a routine investigation before assisted reproductive techniques? Fertil Steril., 95(1):272-276.

8. Gajbhiye $R$ and Gajbhiye R. (2017): Distension Media and Fluid Management Machines. Mastering the Techniques in Hysteroscopy. International Journal of Womens Health and Reproduction Sciences, 139-144.

9. Godinjak $Z$ and Idrizbegovic E. (2018): Should diagnostic hysteroscopy be a routine procedure during diagnostic laparoscopy in infertile women? Bosn J Basic Med Sci. $8(1): 44-47$.

10. Johnstone EB and Olpin JD. (2018): Advanced Imaging Techniques Used in the Infertile Female. In Emerging Topics in Reproduction (pp. 89-113). Springer, Cham.

11. Muhammad K, Ahmad J, Sajjad $M$ and Baik SW. (2016): Visual saliency models for summarization of diagnostic hysteroscopy videos in healthcare systems. SpringerPlus, 5(1), 1495-1451.
12. Nigam A, Saxena $P$ and Mishra A. (2015): Comparison of Hysterosalpingography and Combined Laparohysteroscopy for the Evaluation of Primary Infertility. Kathmandu Univ Med J (KUMJ)., 13(52): 281-285.

13. Pansky M, Feingold M, Sagi R, Herman A, Schneider D and Halperin R. (2016): Diagnostic hysteroscopy as a primary tool in a basic infertility workup. JSLS: Journal of the Society of Laparoendoscopic Surgeons, 10(2), 231-235.

14. Park MG and Isaacson KB. (2017): Hysteroscopic Management of Intrauterine Disorders: Polypectomy, Myomectomy, Endometrial Ablation, Adhesiolysis, and Removal of Uterine Septum. In Clinical Reproductive Medicine and Surgery, 345-370.

15. Pundir J and El Toukhy T. (2010): Uterine cavity assessment prior to IVF. Womens Health (Lond Engl), 6(6):841-848.

16. Wadhwa L, Rani $P$ and Bhatia P. (2017): Comparative prospective study of hysterosalpingography and hysteroscopy in infertile women. Journal of human reproductive sciences, 10(2), 73-81. 


\section{دور منظار الرحم التشخيصي في النساء اللاتى يعانين من ثأخر

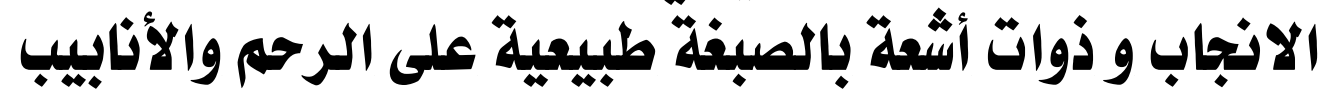

عمرو منصور سليمان سليم، السيذ محمد طه، أحمد شعبان محمد

قسم التوليد وأمراض النساء، كلية الطب، جامعة الأزهر

E-mail: $\underline{\text { dramrmansour28@yahoo.com }}$

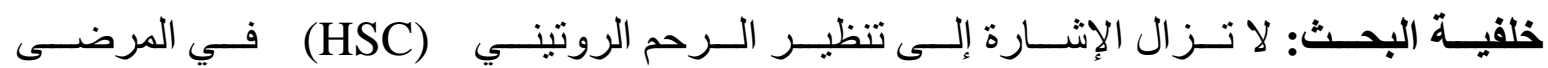

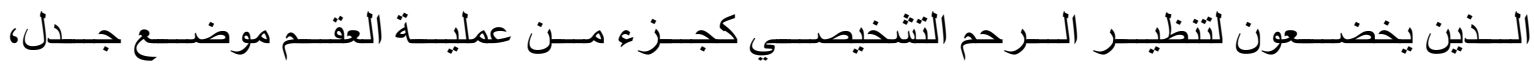

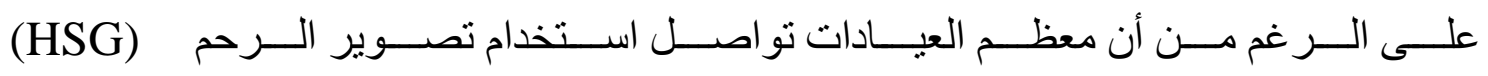

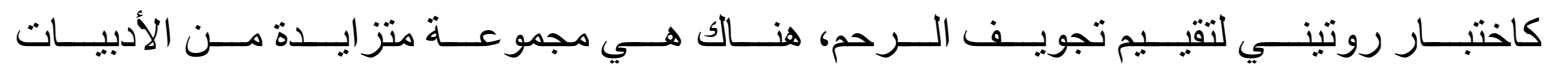

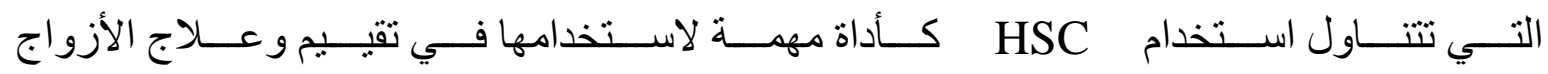

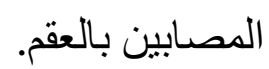

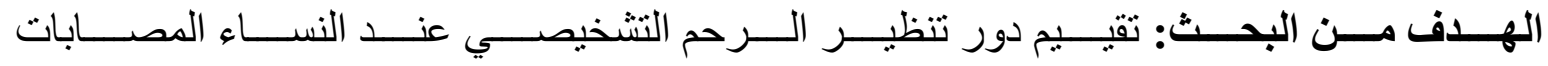
بالعقم المصابات بـ HSG الطبيعي.

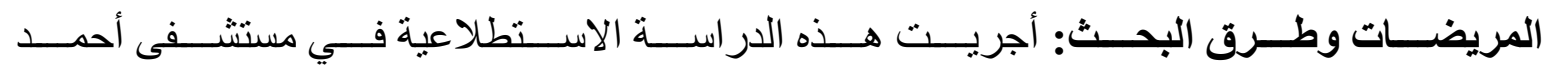

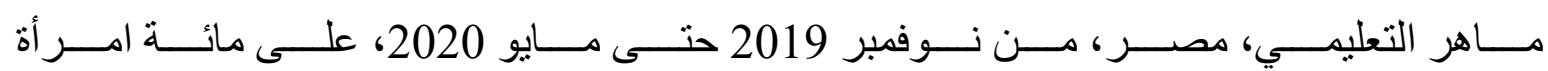

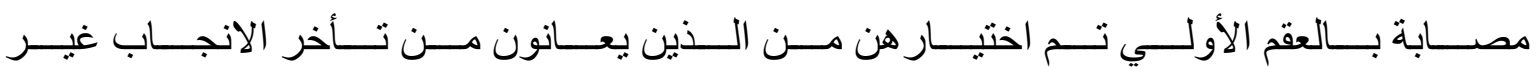

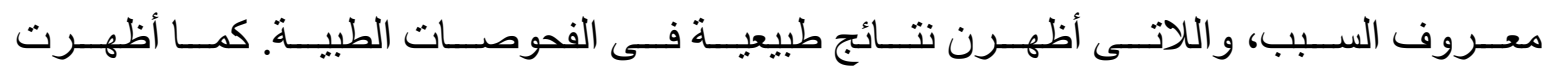

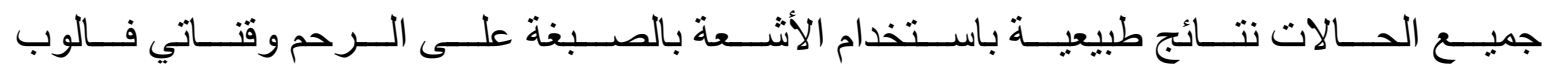

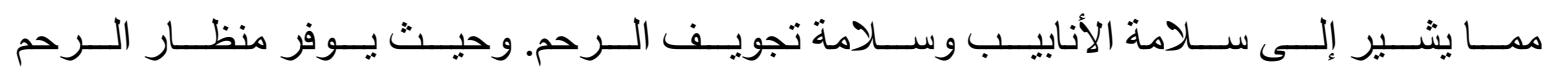

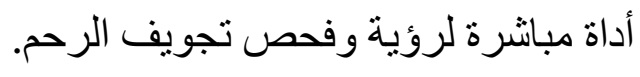

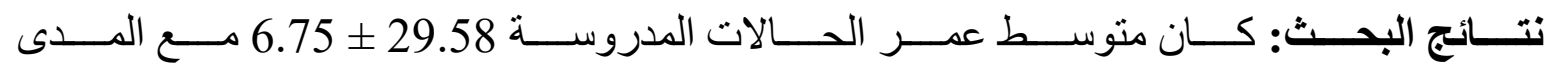

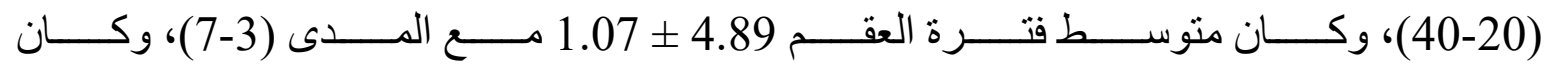

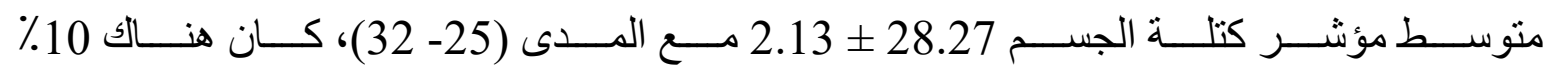

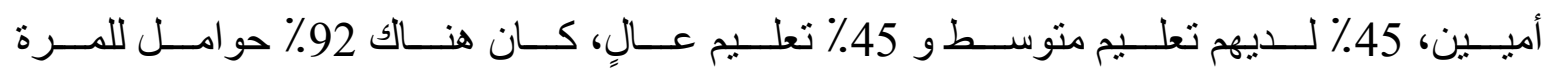

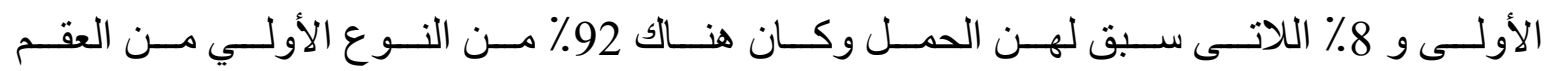

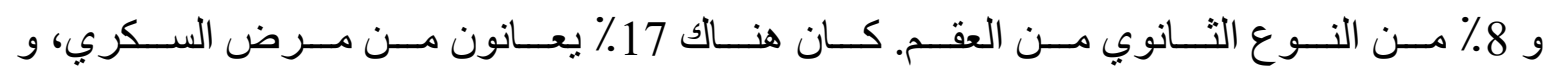




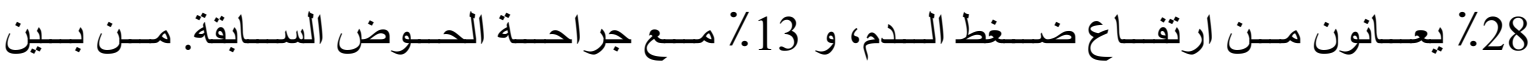

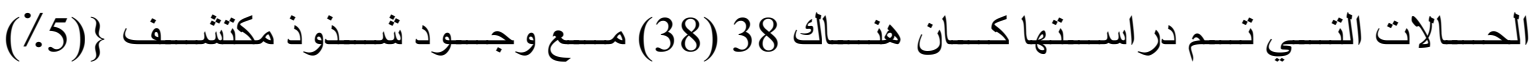

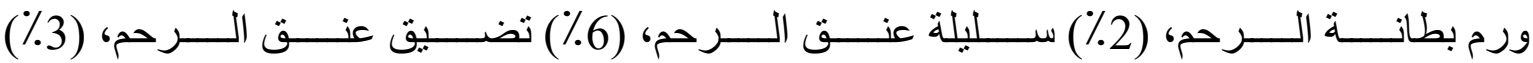

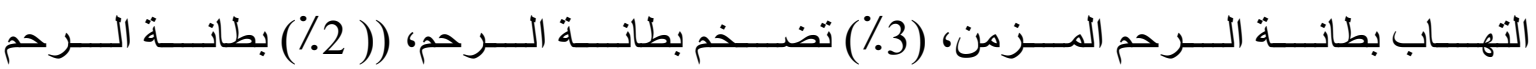

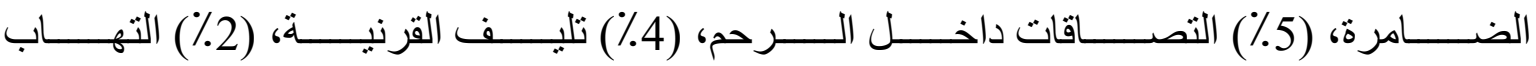

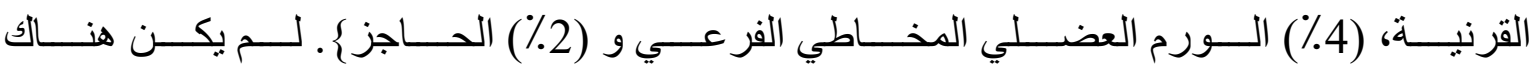

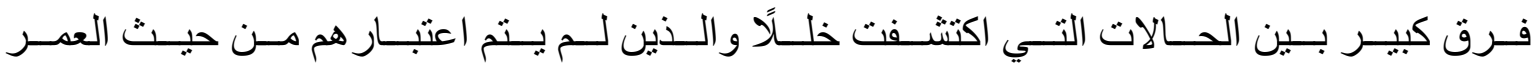

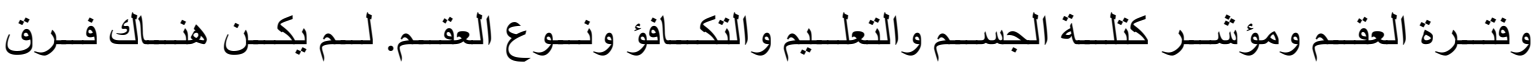

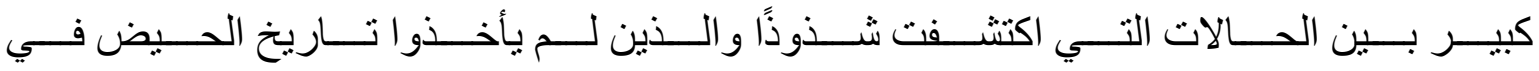

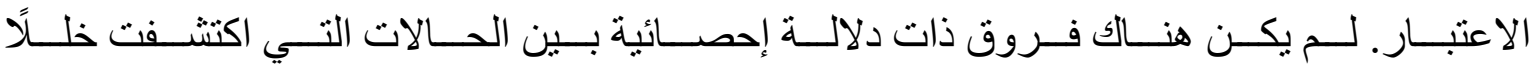

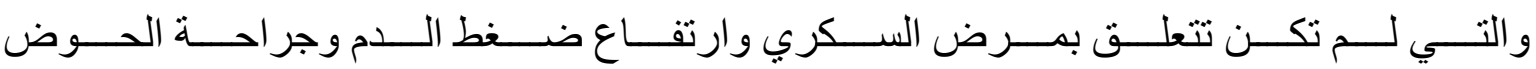

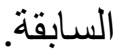

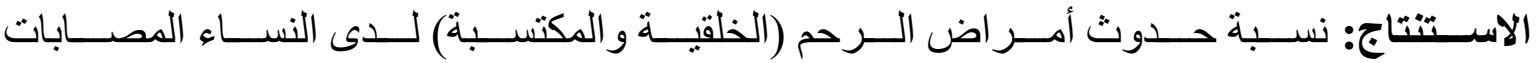

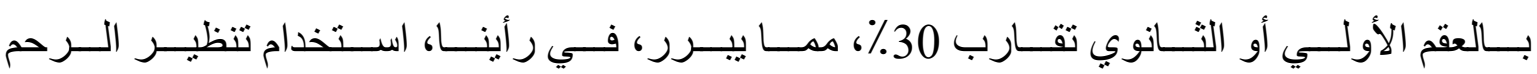
التشخيصي في الفحص الروتيني الأولي للنساء المصابات بالعقم. الكلمـــات الدالـــة: منظـــار الــرحم التشخيصــى، العقــم، الأشـــعة بالصـــبغة علــى الــرحم

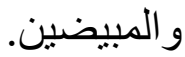

